\title{
A Retrospective Analysis of the Pre-Season Screen Used in a Professional Ballet Company with Recommendations for Improvements in the Screen
}

\author{
K. Robinson, A. Gowen, A. Krichau, C. Garcia, A. Henley, Pat Sells \\ Belmont University, Nashville, TN, USA \\ Email: kevin.robinson@belmont.edu
}

How to cite this paper: Robinson, K., Gowen, A., Krichau, A., Garcia, C., Henley, A. and Sells, P. (2018) A Retrospective Analysis of the Pre-Season Screen Used in a Professional Ballet Company with Recommendations for Improvements in the Screen. Open Access Library Journal, 5: e4806.

https://doi.org/10.4236/oalib.1104806

Received: July 30, 2018

Accepted: September 17, 2018

Published: September 20, 2018

Copyright $\odot 2018$ by authors and Open Access Library Inc.

This work is licensed under the Creative Commons Attribution International License (CC BY 4.0).

http://creativecommons.org/licenses/by/4.0/

\begin{abstract}
Objectives: The primary objective was to determine if the current pre-season screen used by the Nashville Ballet was identifying dancers at risk for injury and determining the injury rates and patterns of injury within the company. The secondary purpose of this study is to propose more objective measurement tools to enhance the pre-season screen. Background: Professional ballet dancers are at an increased risk for lower extremity injuries. Dance USA developed a pre-season health screen intended to identify medical or musculoskeletal conditions that may limit a dancer's ability to participate. Methods: Past screen history from the 2007-2014 seasons was obtained from 285 medical records. The ability of the established pre-season screen to predict injury among the injured dancers was determined by noting side-to-side differences specifically in the manual muscle tests and functional movement analysis portions of the screen. In 2015, seventeen professional dancers from the Nashville Ballet (11 female and 6 male) were included in the study. Manual muscle testing was performed using hand dynamometry on the gluteus maximus and gluteus medius muscles of each subject.3D motion analysis (MyoMotion) recorded dancers performing demi-plies on the right and left sides in parallel and in turnout. Paired samples t-tests were run with a Bonferroni correction and significance was set at $\mathrm{p} \leq 0.05$. Results: All injuries reported during the 2007-2014 seasons were in the lower extremity. Previous pre-season screen data showed the following: Manual muscle testing identified side-to-side gluteus medius differences in $26.92 \%(n=26)$ and gluteus maximus side-to-side differences in $80 \%(\mathrm{n}=5)$ of injured dancers. Visual assessment of alignment while performing a plie in parallel and in turnout identified side-to-side differences in $23.08 \%$ and $26.92 \%$ respectively of the
\end{abstract}


injured dancers. When assessing strength with the hand dynamometer, a significant difference was found between right and left gluteus maximus strength in percent body weight $(\mathrm{p}<0.000)$ and right and left gluteus medius strength in percent body weight $(\mathrm{p}<0.025)$. When assessing alignment using MyoMotion Kinematic Analysis, only right and left hip external rotation in turnout was found to be significant $(\mathrm{p}<0.004)$. Conclusion: In this study, we observed that professional ballet dancers are at an increased risk for lower extremity injuries because the current pre-season screen used by professional ballet companies only identifies $25.64 \%$ of side-to-side differences. Adding more objective screening equipment such as the hand dynamometer and $3 \mathrm{D}$ motion analysis is recommended to improve the pre-season screen and to better identify dancers at risk for injury.

\section{Subject Areas}

Orthopedics

\section{Keywords}

Professional Dancer, Injury Screen

\section{Introduction}

Professional ballet requires a collaboration of flexibility, artistry, and strength. While great effort is often put into dancers achieving extreme ranges of flexibility, strength is an area that is often overlooked as an essential part of ballet training. These professionals must perform long hours of repetitive movement patterns in order to master a specific ballet choreography. This can lead to asymmetrical weakness, predisposing the dancer to injury during the season [1].

One of the fundamental elements of ballet is the ability to perform a demi-plie. Trepman et al. described the demi-plie as a "dance movement in which the upright torso is lowered with hip and knee flexion and ankle dorsiflexion, and then raised back to the starting position; the feet remain flat on the floor throughout the movement [2]." Professional ballet dancers are required to flawlessly perform the demi-plie with both lower extremities; it is an essential building block that will become a necessary movement when performing other challenging maneuvers [2].

A stable pelvis and strong muscles about the hip are imperative for ballet dancers to be able to control their movements and generate power [3]. A stable pelvis helps the dancer control the lower limb as it moves through space and in extreme ranges of motion [3]. In addition, it has been found that the degree of turnout a dancer is able to achieve is influenced by the amount of muscle strength, soft tissue extensibility, and skeletal anatomy [4]. One of the most important muscles for stability about the hip is the gluteus medius [5]. It is a major stabilizer of the pelvis in single limb stance [6]. Boling et al. found that weakness 
of the gluteus medius increased hip adduction and knee valgus angles [7]. Additionally, McMullen et al. examined the role of the gluteus medius with both static and dynamic balance [8]. In this study, single limb static balance, the star excursion balance test, and the lateral step down test were assessed before and after a fatiguing exercise protocol for the gluteus medius. The results showed no significant difference between gender, but there was a significant decrease in the three balance assessments. The authors concluded that the gluteus medius played an integral role in lower extremity stability during different functional movements [8].

The gluteus maximus is another key muscle about the hip. It functions as the primary hip extensor and has some secondary qualities as a hip stabilizer [7]. The gluteus medius and gluteus maximus both play a major role in helping transfer the forces from the lower extremities to the pelvis [6].

There has been a limited number of research studies that look at the strength of professional ballet dancers. The most common method found in the literature to measure strength was with isokinetic testing [1] [9] [10] [11]. Studies that employed this method of strength measurement found that ballet dancers have less strength than their peers. The highest torque value found in male and female dancers was found in the hip extensors [9]. In one professional dance company, the hip abductors were found to be $20 \%-40 \%$ weaker than the hip adductors [9]. Dancers will compensate for hip abductor weakness by shifting their center of gravity away from the weak side. This alteration does not coincide with the aesthetic constraints that are necessary for the movements to be performed correctly. More importantly, hip abductor weakness can lead to lower extremity malalignments increasing the opportunity for future injuries to occur. A study by Hamilton et al. found conflicting results. The abductors were stronger than the adductors for both male and female dancers [11]. It was hypothesized in Hamilton's study that this increase in abduction strength was due to the time spent in single limb stance with the opposite leg held in a variety of positions, therefore creating isometric strengthening [11]. Hip weakness compared to peers is a trend that starts early in training. Young dancers were found to have significantly less strength in their hip flexors, internal and external rotators, and adductors than the controls [4].

There is a high association between muscle weakness and injury in ballet [12] [13] [14]. Literature suggests that lower extremity injuries are among the most frequently diagnosed in ballet. The most common lower extremity injuries occurred in these areas of the body: shin, low back, ankle, hip, knee, and foot [15] [16]. Negus specifically found that anterior hip pain (tendinitis or impingement), anteromedial shin pain (shin splints or stress fractures), low back pain, and posterior ankle pain (impingement, ostrigonum, or tendinitis) are the most common [17]. Lower-power outputs in thigh isokinetic testing have been found to result in an increased number of pelvis, leg and foot injuries among male and female dancers [9]. 
In athletic populations, dynamic stability of the hip in single leg stance activities has been found to be negatively affected by decreased gluteus maximus strength in healthy individuals [17]. In subjects with chronic ankle instability, it was found that hip abductor strength was significantly weaker when compared to the uninvolved side [18]. Female athletes with self-reported low back pain had greater side-to-side differences in proximal hip muscular strength than healthy females [19]. Nadler et al. validated that decreased hip stabilizers can be effected from previous lower extremity injuries [19].

There have been few ballet studies that have quantified specific hip positions while performing a plie [20]. Multiple studies have been conducted on single limb stance in the general population. Injuries occurred when the hip was in adduction and internal rotation, which indicates the relationship between lower extremity injuries and hip alignment when landing from a jump [21]. Nguygen found decreased gluteus maximus activation lead to increased hip internal rotation [17]. Bowerman reported that increased hip internal rotation affects the dynamic stability of the hip and causes abnormal alignment during single-limb weight bearing activities, which is a position used frequently during ballet [22].

Dance USA developed a health screen intended to identify injury and illness risk factors of dancers for the purposes of identifying medical or musculoskeletal conditions that may limit a dancer's ability to participate [23]. Professional dance companies throughout North America utilize this screen. The screen consists of a patient medical history and physical assessment. The physical assessment has eight categories including: 3 minute step test, postural assessment, 9-point Beighton Hypermobility test, passive range of motion, strength/functional tests, shoulder assessment, balance in unilateral stance, functional movement analysis. Manual muscle testing is included as part of the strength/functional tests and is scored using a $0-5$ scale. While this system does allow the clinician to quickly determine if weakness is present, this system is not sensitive enough to detect subtle side to side differences in strength nor does this system allow for comparisons between dancers. For example, Nadler et al. found that female basketball players who had greater than a $10 \%$ side to side difference in hip extensor strength had a significantly higher incidence of lower back pain [18].

Hand dynamometry is an alternative and more objective method of measuring isometric force abilities of a muscle in kilograms $(\mathrm{kg})$; thus creating a more quantitative system of assessing muscle force than solely relying on the subjective view of the physical therapist's zero to five grading scale [19]. Using a hand-held device, this measurement involves assessing peak isometric force of a muscle, measured in kilograms, when loading the muscle under resistive compression in a standardized position [20]. Wadsworth compared the reliability of manual muscle testing using the 0 - 5 scale versus hand dynamometry. The results showed manual muscle testing using the $0-5$ scale to be reliable at detecting only large amounts of noticeable muscular differences between sides [20]. However, the 0 - 5 manual muscle testing scale was unable to determine small variations of muscular differences between sides, particularly between the scores 
of four and five using this system [20]. In these ranges between a four and a five the physical therapist subjectively decides the amount of resistance to give during the test. Wadsworth found muscle testing with a hand-held dynamometer to provide more objective, consistent measurements of isometric muscular force values [20].

There have been numerous articles looking at the biomechanics of lower extremity injuries and the differences between male and female athletes. One of the articles by Mendiguchia et al. [21] makes the following conclusions:

Dancers perform plies in parallel and turnout as part of the functional movement analysis. Plies are evaluated visually in the frontal plane for proper alignment based on observation by the physical therapist. The purpose of this study was to determine if the current pre-season screen used by the Nashville Ballet identified dancers at risk for injury and to determine injury rates and patterns of injury within the company. The secondary purpose of this study is to propose more objective measurement tools to enhance the pre-season screen.

\section{Material and Methods}

This investigation was approved by the Belmont University Institutional Review Board. Each dancer completed a written informed consent prior to testing. Applicable injury history (2007-2014) and past screen history were obtained and recorded from 285 medical records stored at the off-site physical therapy clinic. For the 2014-2015 dance season, two additional items were added to the Dance USA pre-season screen administered by the Nashville Ballet: gluteus maximus and gluteus medius hip strength using a hand dynamometer (Lafayette Instruments, model 01165) and degrees of hip motion in the frontal and transverse planes using the MyoMotion Kinematic Analysis System version MR 3.6.

\subsection{Subjects}

Subjects included 11 female $(25.64 \pm 2.54$ years $)$ and 6 male $(25.67 \pm 4.93$ years $)$ professional dancers. A summary of the participant demographics is included in Table 1. At the time of testing, all subjects were apprentices or first company dancers with the Nashville Ballet. Data was collected during the pre-season screen required for each dancer. Screens were conducted at the physical therapy clinic affiliated with the Nashville Ballet.

\subsection{Instrumentation}

Dynamometry strength assessments were performed using a Lafayette Instrument Company handheld dynamometer Model 01163 with an accuracy of $+1 \%$ or +0.2 lbs (Lafayette Instrumentation Company, Lafayette, Indiana). The analysis of dynamic joint angles was measured using MyoMotion Kinematic Analysis System version MR 3.6. This system uses inertial sensors (7) that have an pitch/roll accuracy of 0.25 degrees (SD of 0.3 degrees) and heading accuracy of 1.25 degrees (SD of 0.5 degrees) (Noraxon, Scottsdale, Arizona). 
Table 1. Demographics.

\begin{tabular}{ccccc}
\hline Sex & & Age (years) & Weight $(\mathrm{kg})$ & Height $(\mathrm{cm})$ \\
\hline Female & Mean & 25.64 & 52.66 & 164.41 \\
& $\mathrm{~N}$ & 11 & 11 & 11 \\
& Std. Deviation & 2.541 & 3.415 & 4.149 \\
Male & Mean & 25.67 & 71.82 & 175.05 \\
& $\mathrm{~N}$ & 6 & 6 & 6 \\
& Std. Deviation & 4.926 & 5.007 & 6.139 \\
Total & Mean & 25.65 & 59.42 & 168.16 \\
& N & 17 & 17 & 17 \\
& Std. Deviation & 3.408 & 10.208 & 7.072 \\
\hline
\end{tabular}

\subsection{Testing Procedures}

Of the 285 medical records from the 2007-2014 seasons, 26 injuries were reported. An injury was defined as an occurrence that required treatment at the off-site physical therapy clinic for more than one visit and resulted in the performer missing practice or performances. The ability of the established pre-season screen to predict injury among the injured dancers was determined by noting side-to-side differences specifically in the manual muscle test and functional movement analysis components of the screen (Table 2).

Each dancer completed a health history questionnaire as part of their annual pre-season screen. Hand dynamometry was performed on gluteus maximus and gluteus medius on each subject. All tests were conducted on a high-low table. Testing position for each muscle group was in accordance to Daniels and Worthingham [22]. Three trials were conducted consecutively on the right and left side. Subjects were instructed to push with maximal force into the dynamometer when cued. The highest score on each side was recorded. Figure 1 and Figure 2 show the manual muscle testing positions used for gluteus maximus and gluteus medius.

\subsection{Motion Analysis}

A calibration file was collected before each type of movement assessment (plie in parallel or turnout). The MyoMotion software uses and algorithm which calculates the joint centers for the hip, knee and ankle based on the calibration file and the subject's height. This file is used as a reference point from which the motion of each joint is calculated. Each dancer performed five consecutive slow demi-plies on the right and left sides in parallel and in turnout. Each demi-plie in parallel was performed with the dancer standing in center (without the use of the barre) and the hip in anatomical neutral. Each turned out demi-plie trial was performed with the dancer standing in center with the hip in a self-selected amount of turnout. The dancers were not instructed to place the free foot in a specific position. The participants completed each trial barefoot on a sprung 
Table 2. Number and percentage of injuries identified based on side-to-side differences in pre-season Screen.

\begin{tabular}{ccccc}
\hline & $\begin{array}{c}\text { Difference } \\
\text { Side-to-Side }\end{array}$ & $\begin{array}{c}\text { No Difference } \\
\text { Side-to-Side }\end{array}$ & $\begin{array}{c}\text { Percentage } \\
\text { Found }\end{array}$ & $\begin{array}{c}\text { Percentage } \\
\text { Missed }\end{array}$ \\
\hline $\begin{array}{c}\text { Manual Muscle Test } \\
\text { Gluteus Medius }\end{array}$ & 7 & 19 & $26.92 \%$ & $73.08 \%$ \\
$\begin{array}{c}\text { Dynamometry Muscle } \\
\text { Test Gluteus Maximus }\end{array}$ & 4 & 1 & $80.00 \%$ & $20.00 \%$ \\
Plie in Parallel & 6 & 20 & $23.08 \%$ & $76.92 \%$ \\
Plie in Turnout & 7 & 19 & $26.92 \%$ & $73.08 \%$ \\
\hline
\end{tabular}

${ }^{*}$ The Nashville Ballet included hand dynamometrytesting of the gluteus maximus beginning in the 2014-2015 season. The remaining data was from the screens from 2007-2014.

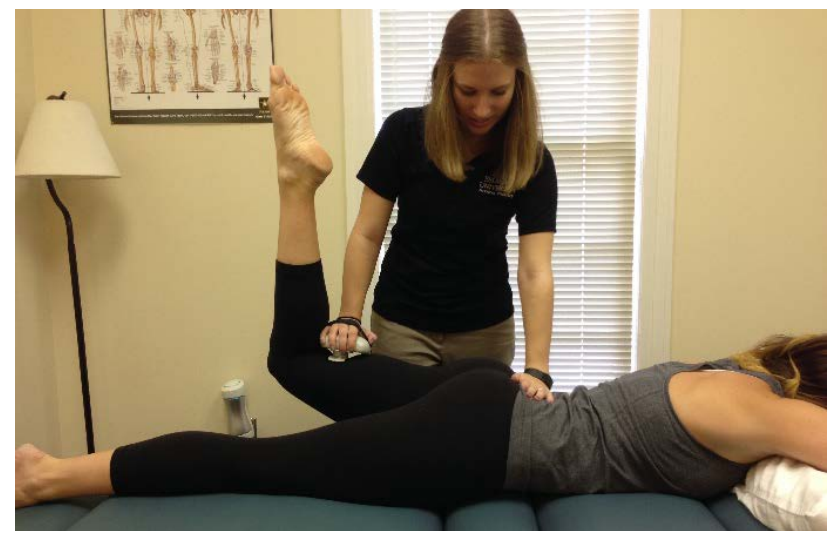

Figure 1. Manual muscle test of gluteus maximus using hand dynamometry.

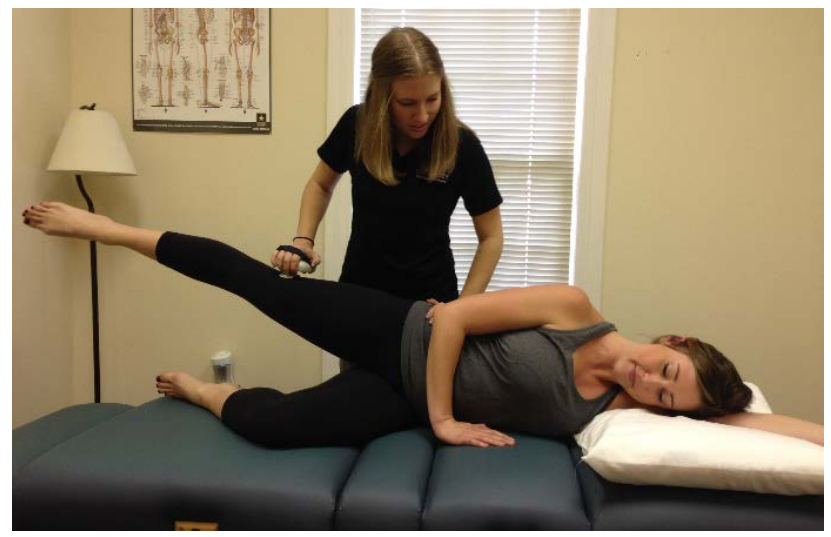

Figure 2. Manual muscle test of gluteus medius using hand dynamometry.

dance floor in front of a full length mirror. Testing occurred in the following order: right side in parallel, right side turnout, left side in parallel, left side turnout. MyoMotion Kinematic Analysis software and sensors were used to record each movement. A total of seven sensors were placed with one at each of the following locations: midline of dorsal surface of each foot in line with the second metatarsal, anterior surface of each tibia midway between knee and ankle, anterior surface of each femur midway between hip and knee, and sacrum. Each 
sensor was attached using the neoprene strap that is included in the MyoMotion kit, with the exception of the foot sensors, which were applied using double sided adhesive stickers. Sensors were calibrated before each dancer's testing session and recalibration prior to each new test motion (plie in parallel or turnout). Figure 3 shows placement of the seven sensors andthe avatar rendered by the MyoMotion Kinematic Analysis software.

\subsection{Statistical Analysis}

The analysis of the 2007-2014 injury data were presented as percentages. The presence or absence of a side-to-side difference compared to the total number of injuries was used to determine the screen's ability to identify potential injuries.

The statistical analysis was conducted using SPSS version 21. Paired samples $\mathrm{t}$-tests were run with a Bonferroni correction. The following means were compared: right and left gluteus medius strength in percent body weight; right and left gluteus maximus strength in percent body weight; right and left hip abduction in parallel; right and left hip abduction in turnout; right and left hip rotation in parallel; right and left hip rotation in turnout. The significance was set at $\mathrm{p} \leq 0.05$. The Bonferroni correction for the analysis comparing gluteus maximus and gluteus medius strength the significance was set at $\mathrm{p} \leq 0.025$. The Bonferroni correction for the analysis comparing rotation and abduction in parallel and in turnout the significance was set at $\mathrm{p} \leq 0.0125$.

\section{Results}

Figure 4 shows the number and type of injuries from the 2007-2014 medical history data. 26 injuries were treated by the physical therapists employed by the Nashville Ballet. Staff physical therapists assessed dancer complaints on-site to determine if further treatment was recommended at the off-site facility. All

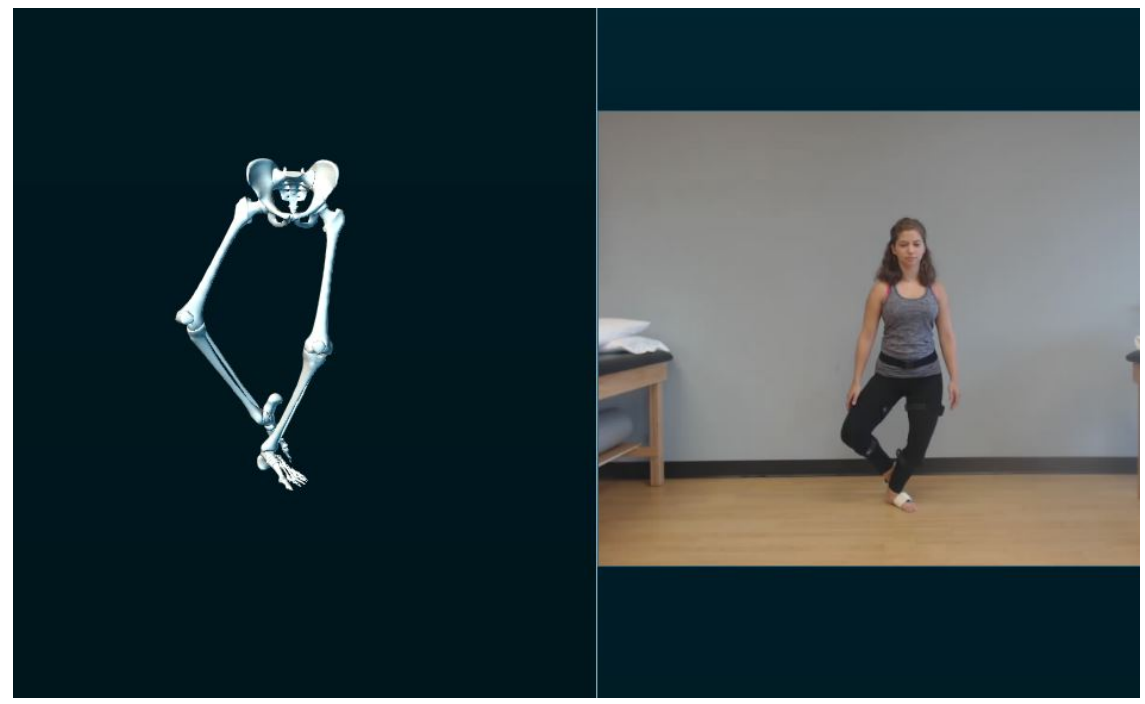

Figure 3. Avatar rendered by MyoMotion Kinematic Analysis software while dancers performed a plie in parallel. 


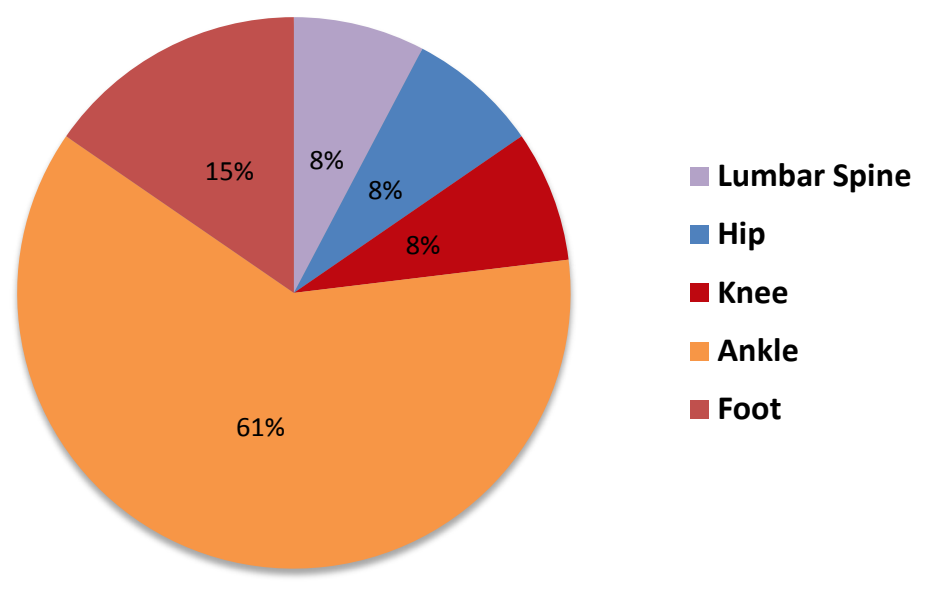

Figure 4. The percentage of injury types and their prevalence among Nashville Ballet dancers from 2007-2014 are shown.

injuries reported were in the lower extremity, with the most injuries occurring at the ankle and foot. Table 4 and Figure 10 display the side-to-side differences identified in the dancers who were injured in the screens conducted between 2007 and 2014. The traditional (0 - 5) manual muscle test grading identified side-to-side gluteus medius differences in $26.92 \%$ of the injured dancers. The Nashville Ballet began dynamometry testing gluteus maximus and medius strength in the 2015 season. Five injuries occurred in the 2015 season and $80 \%$ of those injured had side-to-side gluteus maximus differences, being greater than $10 \%$ difference in side to side values as determined by hand dynamometry. Screens performed prior to 2014-2015 season used visual assessment of lumbopelvic alignment while performing plie in parallel and in turnout. This was done by the practitioner observing for frontal plane hip motion while the dancer performed a plie. This method identified side-to-side differences in $23.08 \%$ and 26.92\% respectively of the injured dancers (Figure 5).

Table 3 presents the dynamometry muscle test strength means relative to percent body weight. A significant difference was found between right and left gluteus maximus strength in percent body weight $(\mathrm{p}<0.000)$. A significant difference was found between right and left gluteus medius strength in percent body weight $(\mathrm{p}<0.025)$. The means are illustrated in Figure 6 .

Table 4 presents the difference between right and left hip external rotation and abduction in parallel and in turnout. A significant difference was found between right and left hip external rotation in turnout $(p<0.004)$. No significant difference was found between right and left hip rotation in parallel $(p<0.182)$, right and left hip abduction in turnout $(\mathrm{p}=0.980)$, and right and left hip abduction in parallel $(\mathrm{p}<0.095)$. The means for plie in parallel and turnout are presented in Figures 7-10.

\section{Discussion}

A significant difference was found in the side-to-side proximal hip strength in 
Table 3. Dynamometry muscle test means.

\begin{tabular}{cc}
\hline & \% Body Weight \\
\hline Right Gluteus Medius $^{\ddagger}$ & $19.86 \pm 4.92$ \\
Left Gluteus Medius $^{\ddagger}$ & $22.23 \pm 5.75$ \\
Right Gluteus Maximus & $22.61 \pm 4.93$ \\
Left Gluteus Maximus $^{*}$ & $17.56 \pm 4.73$ \\
\hline
\end{tabular}

${ }^{\ddagger}$ Gluteus Medius: Left significantly greater than right $(\mathrm{p} \leq 0.05) .{ }^{\star}$ Gluteus Maximus: Right significantly greater than left $(\mathrm{p} \leq 0.05)$.

Table 4. MyoMotion Hip Abduction and rotation means (in degrees).

\begin{tabular}{ccc}
\hline & Parallel & Turnout \\
\hline Right Hip Rotation & $-3.85 \pm 17.51$ & $30.28 \pm 14.06^{*}$ \\
Left Hip Rotation & $2.27 \pm 10.51$ & $40.48 \pm 13.15^{*}$ \\
Right Hip Abduction & $-8.25 \pm 8.48$ & $4.93 \pm 4.48$ \\
Left Hip Abduction & $-11.78 \pm 5.26$ & $4.90 \pm 6.76$ \\
\hline
\end{tabular}

${ }^{*} \mathrm{p}<0.05 ;(-)$ values $=$ internal rotation and adduction; $(+)$ values $=$ external rotation and abduction; Left hip external rotation in turnout was significantly greater than the right.

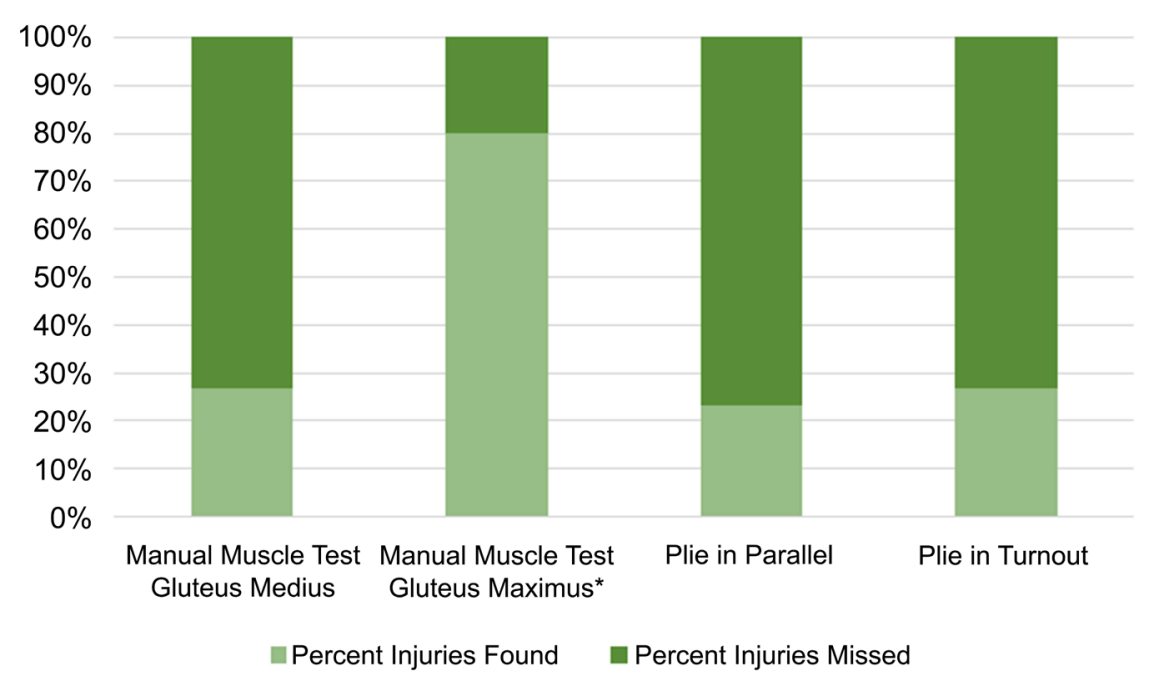

Figure 5. Percentage of Injuries Predicted Based on Side-to-Side Differences in Pre-season Screen. ${ }^{\star}$ The Nashville Ballet included the manual muscle test of the gluteus maximus in the 2014 season only.

professional ballet dancers. The right gluteus maximus was found to be stronger than the left. The opposite was found in gluteus medius, with the left side being significantly stronger than the right side. Proximal hip muscle strength is necessary for dancers to maintain neutral pelvis alignment [3]. Previous research has found that dancers who have a side-to-side strength deficit are at an increased risk for lower extremity injury, but no specific parameters have been established [9]. Established norms have been found using a hand dynamometer for the athletic population; it has been found that female basketball players with a $10 \%$ 


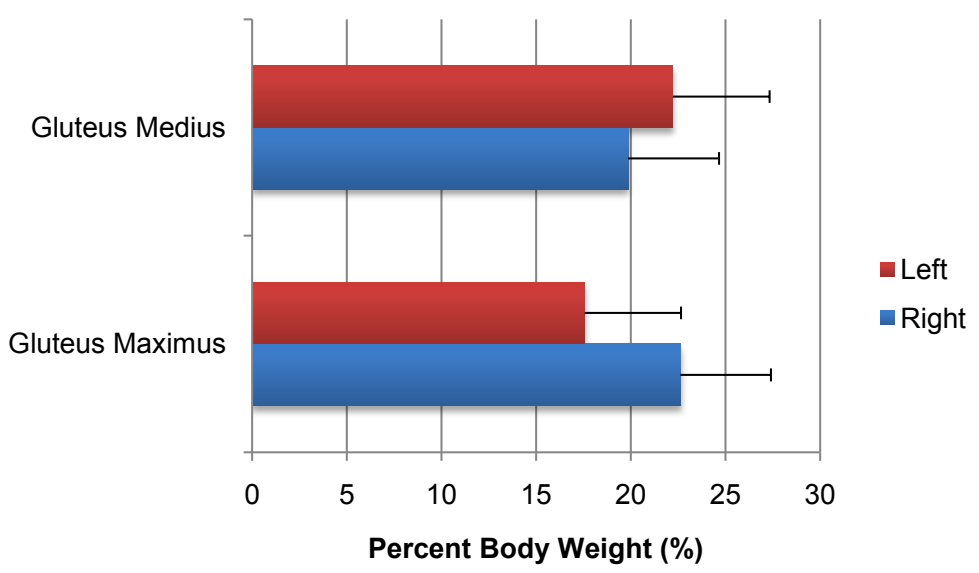

Figure 6. Dynamometry muscle test of the gluteus medius and gluteus maximus. Gluteus Medius: Left significantly greater than right $(\mathrm{p} \leq 0.05)$; Gluteus Maximus: Right significantly greater than left $(\mathrm{p} \leq 0.05)$.

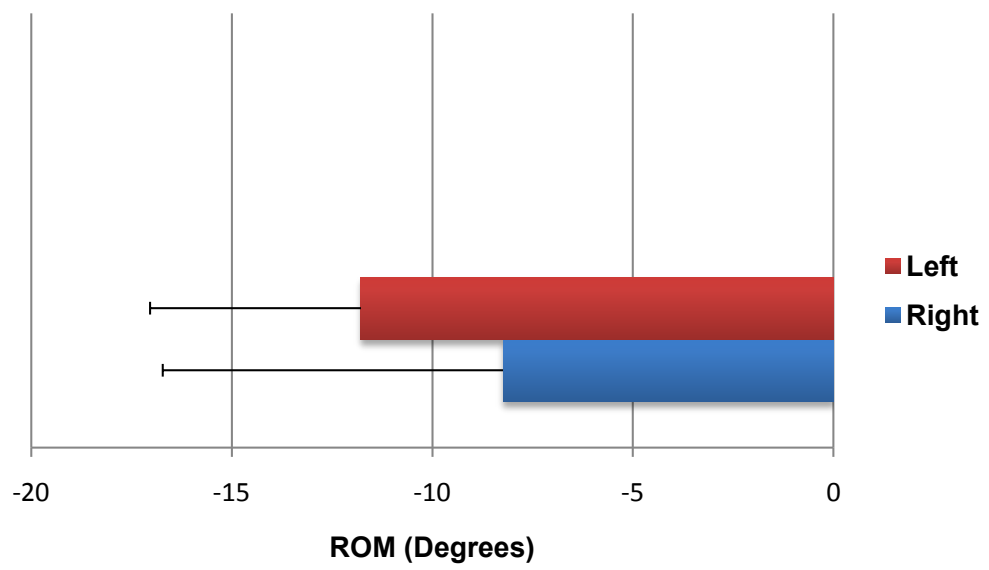

Figure 7. The difference between the means (right - left) of hip adduction range of motion (ROM) measurements while performing plie in parallel with standard deviations shown.

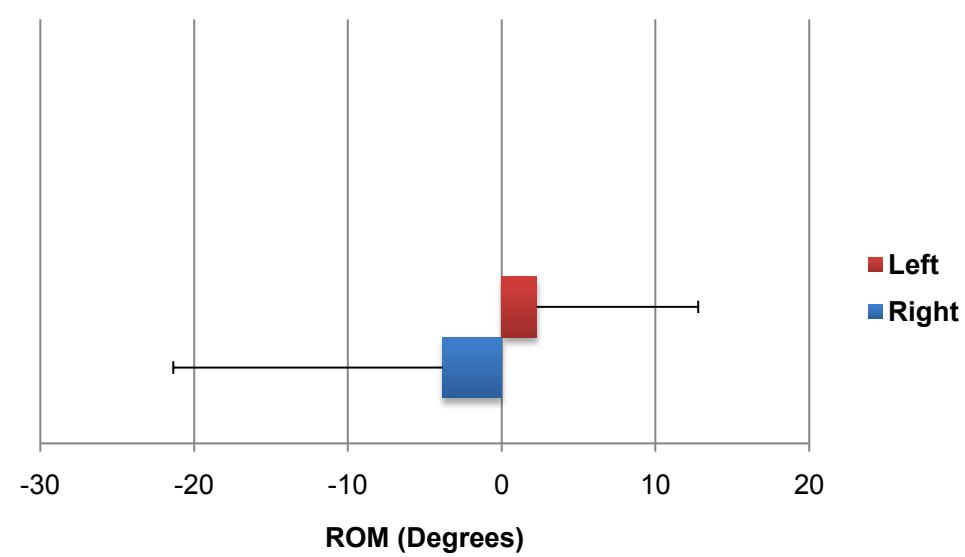

Figure 8. The difference between the means (right - left) of hip rotation measurements while performing plie in parallel with standard deviations shown. $(-)$ values $=$ internal rotation; $(+)$ values $=$ external rotation. 


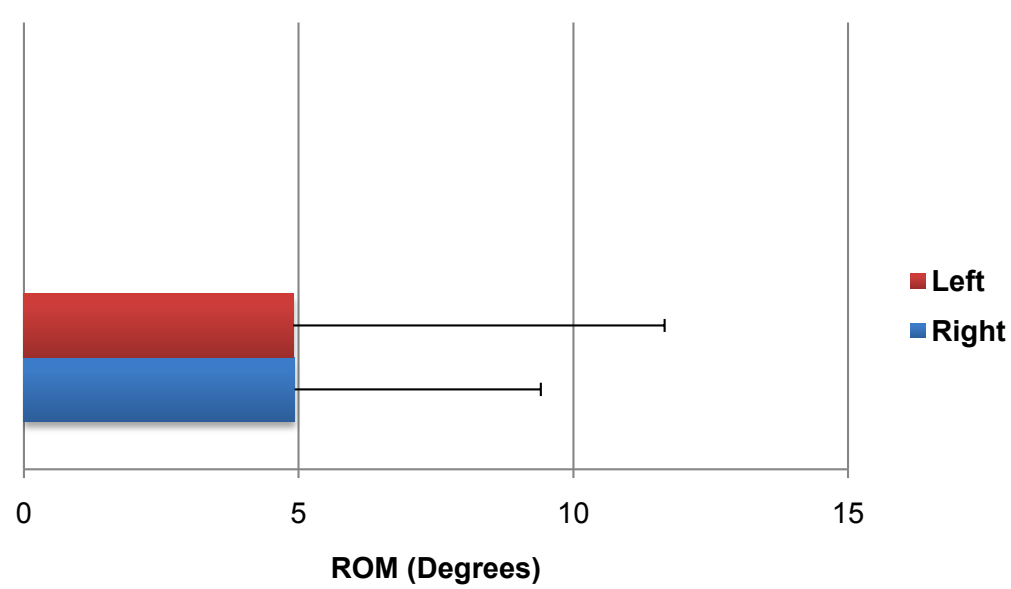

Figure 9. The difference between the means (right - left) of abduction range of motion (ROM) measurements while performing plie in turnout with standard deviations shown.

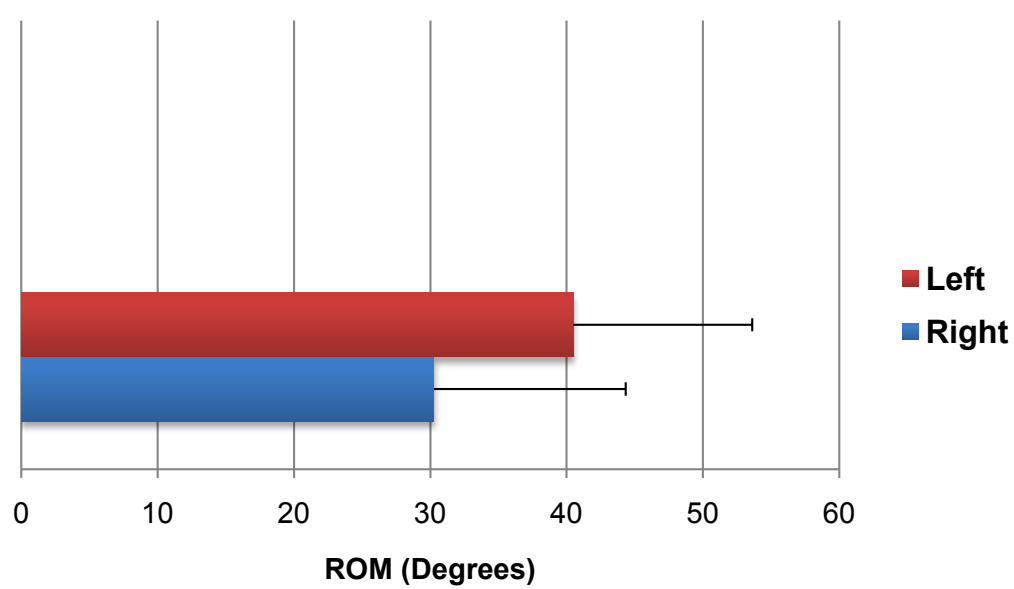

Figure 10. The significant difference between the means (right and left) of hip rotation range of motion (ROM) measurements while performing plie in turnout with standard deviations shown.

side-to-side difference in gluteus maximus strength were more prone to have low back pain [24]. This relationship is relevant to this study as shown by the data collected during the Nashville Ballet's 2007-2014 seasons. Lumbar spine injuries accounted for $8 \%$ of the total injuries. Future research is necessary to create objective strength norms specific to professional ballet dancers.

Reference values for gluteus medius strength in average healthy adults have been found using a handheld dynamometer [25]. When compared to these norms, this study's results indicated that the dancer's tested were found to have dramatically lower gluteus medius strength. According to Bohannon, this would categorize the dancers as being impaired relative to a healthy individual [25]. The current screen utilized by the Nashville Ballet requires a 0 - 5 manual muscle testing scale; this scale may cause strength differences to be overlooked. As evidenced by the injuries in the 2007-2014 seasons, only $26.92 \%$ of the injured dancers' screens found side-to-side differences in gluteus medius strength. The 
Nashville Ballet added hand dynamometry measurements of the gluteus medius and maximus to its screen following the 2014 season, and it identified side-toside differences in gluteus maximus strength in 4 out of 5 injured dancers in 2015. This is a strong indicator that gluteus maximus strength testing should be incorporated into the Dance USA screen. This study elected to measure gluteus maximus and medius strength using a hand dynamometer. The hand dynamometer measures static force from $0-199.9 \mathrm{~kg}$, with reported accuracy to $0.1 \mathrm{~kg} \pm$ $2 \%$ [26]. The sensitivity of the hand dynamometer suggests that it is able to detect subtle differences in strength that traditional manual muscle testing simply cannot.

Dancers were found to have a significant difference between left and right hip external rotation while performing a plie in turnout. The right hip demonstrated limited hip external rotation. These results suggest that the dancers with side-to-side hip alignment imbalances would be at a greater risk for lower extremity injuries. Further research is necessary to create established norms for the appropriate amount of rotation while performing a plie in the professional ballet population.

This study found that dancers had increased adduction on both sides while performing plies in parallel. This adduction was not noted when plies were performed in turnout. Although this difference was not found to be significant, previous research suggests that an increase in hip adduction can decrease the dynamic stability of the hips and predispose an athlete to injury [21]. Individuals with poor hip muscular control may be at a greater risk for the development of LBP secondary to alterations in the transference of forces from the lower limbs up toward the spine [18].

The current screen's Functional Movement Analysis is scored via visual assessment of the frontal plane. Out of the 26 injured dancers from the previous seasons' screens, a side-to-side difference was not found in 19 dancers (73.08\%) while performing a plie in parallel, and not found in 20 dancers (76.92\%) while performing a plie in turnout. MyoMotion Kinematic Analysis software was used in this study to objectively measure the alignment of the hip at any instance throughout the dancers' movement. This software uses sensors to measure joint angles and provide specific values of range of motion in degrees. An advantage of this inertial system is that it has the ability to provide three dimensional data without compromising the dancer's movements. When using 3D motion analysis, the dancers were found to have a significant difference between left and right hip external rotation while performing a plie in turnout. Our results suggest that the MyoMotion inertial system provides a reliable method for conducting a functional movement assessment and may represent a viable quantitative clinical movement analysis solution for conducting functional 3D assessments.

Consistent with previous research, this study gathered that the most common injuries occurred primarily in the lumbar spine, hip, knee, ankle, and foot [11] [12] [13]. By adding more objective measures to the existing screen, more accu- 
rate weaknesses and alignment deficits can be identified. The use of a hand dynamometer for strength assessment and the use of a 3D motion analysis system for functional movement assessment is recommended to improve the current pre-season screen in order to better identify dancers at risk for injury.

The recommendations for adding the hand dynamometer and 3D analysis does present a cost to the screening process. However, if the screen would be improved in identifying at risk performers, then the cost of these devices would be more than covered by the medical savings with fewer injuries. The cost of a hand dynamometer is approximately $\$ 1000.00$ (US) versus the medical cost of just one lower extremity injury. Additionally, obtaining more objective strength data would allow the combining of data between dance companies so that we could further enhance the screening and return to performing guidelines. The 3D analysis systems are considerably more expensive, however regional centers could be identified for testing which would lower the cost.

\section{Conclusions}

The results of this study show that lower extremity injuries were most prevalent among the Nashville Ballet throughout the previous seven seasons. Significant side-to-side differences were found in the strength of the gluteus maximus and medius in professional ballet dancers. A significant difference was also found in the amount of hip external rotation while performing a plie in turnout.

In this study, we observed that professional ballet dancers are at an increased risk for lower extremity injuries and the current pre-season screen used by professional ballet companies only identifies $25.64 \%$ of side-to-side differences. We recommend incorporating more objective screening assessments such as the hand dynamometer and the use of 3D motion analysis to improve the pre-season screen currently used in order to more effectively identify dancers at risk for lower extremity injuries and to prevent these injuries from occurring. Future research is needed to establish strength and alignment normative values specific to the professional ballet population. These values will help to better identify professional ballet dancers at risk for potential injuries.

\section{Acknowledgements}

We would like to thank the Nashville Ballet and physical therapists Lindsay Ison and Christie Rose for their help with this study.

\section{Conflicts of Interest}

The authors declare no conflicts of interest regarding the publication of this paper.

\section{References}

[1] Koutedakis, Y. and Jamurtas, A. (2004) The Dancer as a Performing Athlete Physiological Considerations. Sports Medicine, 34, 651-661. 
[2] Trepman, E., Gellman, R.E., Solomon, R., Murthy, K.R., Micheli, L.J. and De Luca, C.J. (1994) Electromyographic Analysis of Standing Posture and Demi-Plie in Ballet and Modern Dancers. Medicine \& Science in Sports \& Exercise, 771-782.

[3] Gupta, A. (2001) An Evaluation of Differences in Hip External Rotation Strength and Range of Motion between Female Dancers and Non-Dancers. British Journal of Sports Medicine, 38, 778-783.

[4] Bennell, K. (2001) Changes in Hip and Ankle Range of Motion and Hip Muscle Strength in 8-11 Year Old Novice Female Ballet Dancers and Controls: A 12 Month Follow up Study. British Journal of Sports Medicine, 35, 54-59.

https://doi.org/10.1136/bjsm.35.1.54

[5] Presswood, L., Cronin, J., Keogh, J.W.L. and Whatman, C. (2008) Gluteus Medius: Applied Anatomy, Dysfunction, Assessment, and Progressive Strengthening. Strength \& Conditioning Journal, 30, 41-53. https://doi.org/10.1519/SSC.0b013e318187f19a

[6] Nadler, S.F., Malanga, G.A., Deprince, M., Stitik, T.P. and Feinberg, J.H. (2000) The Relationship Between Lower Extremity Injury, Low Back Pain, and Hip Muscle Strength in Male and Female Collegiate Athletes. Clinical Journal of Sport Medicine, 10, 89-97. https://doi.org/10.1097/00042752-200004000-00002

[7] Boling, M.C., Padua, D.A. and Creighton R.A. (2009) Concentric and Eccentric Torque of the Hip Musculature in Individuals with and without Patellofemoral Pain. Journal of Athletic Training, 44, 7-13. https://doi.org/10.4085/1062-6050-44.1.7

[8] McMullen, K.L., Cosby, N.L., Hertel, J., Ingersoll, C.D. and Hart, J.M. (2011) Lower Extremity Neuromuscular Control Immediately after Fatiguing Hip-Abduction Exercise. Journal of Athletic Training, 46, 607-614. https://doi.org/10.4085/1062-6050-46.6.607

[9] Kushner, S., Reid, D., Saboe, L. and Penrose, T. (1992) Isokinetic Torque Values of the Hip in Professional Ballet Dancers. Clinical Journal of Sport Medicine, 2, 114-120. https://doi.org/10.1097/00042752-199204000-00007

[10] Koutedakis, Y. and Pacy, P.D.G. (1997) Thigh Peak Torques and Lower-Body Injuries in Dancers. Journal of Dance Medicine \& Science, 1, 12-15.

[11] Hamilton, W.G., Hamilton, L.H., Marshall, P. and Molnar, M. (1992) A Profile of the Musculoskeletal Characteristics of Elite Professional Ballet Dancers. The American Journal of Sports Medicine, 20, 267-273. https://doi.org/10.1177/036354659202000306

[12] Bronner, S., Ojofeitimi, S. and Rose, D. (2011) Injuries in a Modern Dance Company: Effect of Comprehensive Management on Injury Incidence. Journal of Dance Medicine \& Science, 15, 116-122.

[13] Hincapié, C., Morton, E. and Cassidy, J. (2008) Musculoskeletal Injuries and Pain in Dancers: A Systematic Review. Archives of Physical Medicine and Rehabilitation, 89, 1819-1829. https://doi.org/10.1016/j.apmr.2008.02.020

[14] Solomon, R., Micheli, L., Solomon, J. and McGray Jr., E. (1999) The Cost of Injuries in a Professional Ballet Company. Medical Problems of Performing Artists, 14, 164-169.

[15] Coplan, J. (2002) Ballet Dancer's Turnout and Its Relationship to Self-Reported Injury. The Journal of Orthopaedic and Sports Physical Therapy, 32, 579-584. https://doi.org/10.2519/jospt.2002.32.11.579

[16] Garric, J.G. (1986) Ballet Injuries. Medical Problems of Performing Artists, 1, 
123-127.

[17] Negus, V., Hopper, D. and Briffa, N.K. (2005) Associations between Turnout and Lower Extremity Injuries in Classical Ballet Dancers. The Journal of Orthopaedic and Sports Physical Therapy, 35, 307-318.

https://doi.org/10.2519/jospt.2005.35.5.307

[18] Nadler, S.F., Malanga, G., Feinberg, J.H., Prybicien, M., Stitik, T.P. and DePrince, M. (2001) Relationship between Hip Muscle Imbalance and Occurrence of Low Back Pain in Collegiate Athletes: A Prospective Study. American Journal of Physical Medicine \& Rehabilitation, 80, 572-577. https://doi.org/10.1097/00002060-200108000-00005

[19] Li, R.C., Jasiewicz, J.M., Middleton, J. and Condie, P. (2006) The Development, Validity, and Reliability of a Manual Muscle Testing Device with Integrated Limb Position Sensors. Archives of Physical Medicine and Rehabilitation, 87, 411-417.

[20] Wadsworth, C.T., Krishnan, R., Sear, M., et al. (1987) Intrarater Reliability of Manual Muscle Testing and Hand-Held Dynametric Muscle Testing. Physical Therapy, 67, 1342-1347. https://doi.org/10.1093/ptj/67.9.1342

[21] Mendiguchia, J., Ford, K.R., Quatman, C.E., Alentorn-Geli, E. and Hewett, T.E. (2011) Sex Differences in Proximal Control of the Knee Joint. Sports Medicine, 41, 541-557. https://doi.org/10.2165/11589140-000000000-00000

[22] Hislop, H., Avers, D. and Brown, M. (2014) Daniels and Worthingham's Muscle Testing Techniques of Manual Examination and Performance Testing. 9th Edition.

[23] Dance/USA Task Force on Dancer Health. https://www.danceusa.org/dancerhealth

[24] Nadler, S., Malanga, G., DePrince, M., Stitik, T. and Feinberg, J. (2000) The Relationship between Lower Extremity Injury, Low Back Pain, and Hip Muscle Strength in Male and Female Collegiate Athletes. Clinical Journal of Sport Medicine, 10, 89-97. https://doi.org/10.1097/00042752-200004000-00002

[25] Bohannon, R. (1997) Reference Values for Extremity Muscle Strength Obtained by Hand-Held Dynamometry from Adults Aged 20 to 79 Years. Archives of Physical Medicine and Rehabilitation, 78, 26-32. https://doi.org/10.1016/S0003-9993(97)90005-8

[26] Fredericson, M., Cookingham, C., Chaudhari, A., Dowdell, B., Oestreicher, N. and Sahrmann, S. (2000) Hip Abductor Weakness in Distance Runners with Iliotibial Band Syndrome. Clinical Journal of Sport Medicine, 10, 169-175.

https://doi.org/10.1097/00042752-200007000-00004 